ARTIGO ORIGINAL

\title{
Eficiência de cinco índices de perigo de incêndios para o município de Jataí - GO
}

\author{
Efficiency of five fire risk index for Jataí - GO \\ Darliane Mariano Gonçalves ${ }^{1}$ (1), Daniela Pereira Dias ${ }^{1}$ \\ ${ }^{1}$ Universidade Federal de Jataí - UFJ, Jataí, GO, Brasil
}

Como citar: Gonçalves, D. M., \& Dias, D. P. (2020). Eficiência de cinco índices de perigo de incêndios para o município de Jataí - GO. Scientia Forestalis, 48(127), e3362. https://doi.org/10.18671/scifor.v48n127.24

\begin{abstract}
Resumo
O objetivo deste estudo foi determinar a eficiência de cinco índices de perigo de incêndios para o município de Jataí - GO, no período de 2007 a 2016. Foram utilizados dados da estação meteorológica, da Rede Nacional de Monitoramento do Instituto Nacional de Meteorologia (INMET), e de focos de calor, obtidos no Instituto Nacional de Pesquisas Espaciais (INPE). Foram calculados cinco índices de perigo de incêndios: Angstron, Nesterov, Telecyn, Fórmula de Monte Alegre (FMA) e Fórmula de Monte Alegre Modificada (FMA+). Tanto as médias das variáveis meteorológicas quanto o número total de focos e as classes de perigo de incêndios variaram entre os meses, mas o mesmo não ocorreu entre os anos estudados. A umidade relativa do ar, a temperatura do ponto de orvalho de Jataí e o índice de Angstron apresentaram maior correlação com a média mensal do número de focos de calor. As médias das variáveis meteorológicas correlacionaram-se com o número de dias por mês em que foram identificados perigo de incêndios (nas classes - médio, alto, grande muito alto e perigosíssimo), exceto a temperatura do ar. O índice de Telecyn, seguido do índice de Angstron e FMA+, mostraram-se mais eficientes para Jataí, pela análise de desempenho de Skill Score e porcentagem de sucesso.
\end{abstract}

Palavras-chave: Cerrado; Focos de calor; Prevenção de incêndios; Variáveis meteorológicas.

\begin{abstract}
The objective of this study was to determine the efficiency of the five fire risk index in Jataí County, Goiás, from 2007 to 2016. Data were used from the meteorological station from the National Institute of Meteorology (INMET) and fire foci selected from the National Institute for Space Research (INPE). Five fire risk indices were calculated: Angstron, Nesterov, Telecyn, Formula Monte Alegre (FMA) and Formula Monte Alegre Modified (FMA+). As much as the meteorological variables as the total number of fire foci and the classes of fire risk varied between the months, but the same did not happen between the studied years. Air relative humidity, dew point temperature and Angstron index were more correlated with the monthly number of fire foci. Meteorological variables correlated with the number of fire risk have been identified (classes - medium, high, very high and dangerous); except for air temperature. The Telecyn index, followed by the Angstron index and FMA+, is more efficient for Jataí, by analyzing Skill Score performance and success percentage.
\end{abstract}

Keywords: Cerrado; Fire foci; Fire prevention; Meteorological variables.

\section{INTRODUÇÃO}

A relação do cerrado com o fogo tem repercutido muito nos últimos anos, sobretudo para que sejam indicados quais os reais efeitos, positivos e negativos, do fogo sobre a vegetação. Alguns pesquisadores consideram que o cerrado seja dependente do fogo, sendo este um fator crucial para a manutenção da estrutura, biodiversidade e funcionamento dos

Fonte de financiamento: Nenhuma.

Conflito de interesse: Nada a declarar.

Autor correspondente: danieladias@ufg.br

Recebido: 8 maio 2019.

Aceito: 24 setembro 2019

Editor: Paulo Henrique Müller Silva.

(c) (i) Este é um artigo publicado em acesso aberto (Open Access) sob a licença Creative Commons Attribution, que permite uso, distribuição e

c) reprodução em qualquer meio, sem restrições desde que o trabalho original seja corretamente citado. 
ecossistemas (Durigan \& Ratter, 2016; Schmidt et al., 2016). Porém, por outro lado, outros estudos indicam que o fogo apresenta efeitos negativos sobre o ambiente natural (destruição de habitats, mortalidade de animais, entre outras), bem como sobre a saúde humana, a sociedade e sua economia e, também, ao clima global, por meio da emissão de carbono na atmosfera (Frizzo et al., 2011; Medeiros \& Miranda, 2005). Independentemente das consequências do fogo na vegetação, as condições climáticas do Cerrado, principalmente as associadas ao período seco, propiciam a ocorrência e a propagação do fogo (Durigan \& Ratter, 2016), assim como as atividades agrícolas desenvolvidas no domínio deste bioma, que também podem causar incêndios.

A ocorrência de incêndios relaciona-se com a temperatura do ar, a umidade relativa do ar, a direção e velocidade do vento e a precipitação (Soriano et al., 2015; Torres et al., 2011). As umidades do ar e do material combustível atuam como um fator para a ignição do fogo, enquanto o vento auxilia na propagação e a ausência de precipitação e a diminuicão da umidade colaboram para que os incêndios ocorram. Além disso, as variáveis meteorológicas são utilizadas frequentemente para se prever a ocorrência de incêndios a partir de índices de perigo de incêndios (Borges et al., 2011; Soriano et al., 2015; Torres et al., 2011).

Vários índices de perigo de incêndios tem sido testados em diferentes locais (Torres et al., 2017; Casavecchia et al., 2019), no sentido de indicar qual apresenta melhor desempenho na previsão de ocorrência de incêndios. Isto porque a previsão da ocorrência de incêndios, atividade útil para atuação na prevenção destes, possibilita a identificação dos dias e épocas de maior probabilidade de ocorrência de incêndios e, com essas informações, podem ser tomadas medidas técnicas e administrativas para reduzir o potencial de danos do fogo (Soares \& Batista, 2007). Atualmente, as técnicas de combate direto e indireto aos incêndios florestais, mesmo com seus custos, têm alcançado avanços, mas as técnicas de prevenção não apresentaram o mesmo ritmo de evolução (Nunes et al., 2006; Soriano et al., 2015).

Como a proteção das florestas contra o fogo começa com a prevenção, a melhor maneira de combater um incêndio seria evitando que ele ocorresse. E, considerando que a maioria dos incêndios em vegetação é provocada por ação antrópica, eles são, em sua maior parte, teoricamente evitáveis (Nunes et al., 2006; Sampaio, 1999). Assim, avaliar qual o índice apresenta maior eficiência na previsão de ocorrência de incêndios, dependendo das características meteorológicas locais, tem sido uma estratégia de prevenção e combate a incêndios. $\mathrm{O}$ objetivo deste estudo foi determinar a eficiência de cinco índices de perigo de incêndio no município de Jataí - GO, tendo como base dados diários meteorológicos e de número de focos de calor, no período de 2007 a 2016.

\section{MATERIAL E MÉTODOS}

O estudo foi conduzido a partir de dados do município de Jataí, pertencente à mesorregião sul goiano e microrregião sudoeste de Goiás, que possui área de $7.174,1$ km², e está inserido no bioma Cerrado. Jataí foi considerada uma das cidades que mais produzem milho, soja e leite de Goiás e do Brasil (Instituto Brasileiro de Geografia e Estatística, 2017). O clima da região, segundo a classificação de Köppen, é do tipo Aw - tropical de savana e megatérmico com duas estações bem definidas. O maior índice pluviométrico em Jataí ocorre de outubro a abril e o período de estiagem (precipitação inferior a $50 \mathrm{~mm}$. mês $\mathrm{s}^{-1}$ ) de maio a setembro. A precipitação anual da média histórica do município é de $1651 \mathrm{~mm}$ e a temperatura média anual é de $23,7^{\circ} \mathrm{C}$ (Instituto Nacional de Meteorologia, 2017).

Os dados meteorológicos (precipitação pluvial - mm, temperatura do ar $-{ }^{\circ} \mathrm{C}$, umidade relativa do ar - \%, temperatura do ponto de orvalho $-{ }^{\circ} \mathrm{C}$ e velocidade do vento $-\mathrm{m} . \mathrm{s}^{-1}$ ) foram obtidos na estação meteorológica automática (EMA) da Rede Nacional de Monitoramento do Instituto Nacional de Meteorologia (INMET), identificada como A016 (17 $55^{\circ} \mathrm{S}, 51^{\circ} 43^{\prime} \mathrm{W}$ e altitude de $582 \mathrm{~m}$ ), localizada em Jataí - Goiás. Foram utilizados os dados de uma série temporal de 10 anos (2007 - 2016), considerando a temperatura do ar, umidade relativa do ar, temperatura do ponto de orvalho e velocidade do vento medidas diariamente às $13 \mathrm{~h}$ (horário de Brasília), para posterior cálculo das médias mensais e anuais destas variáveis. Os 
dados de precipitação diária e o número de dias sem precipitação foram contabilizados para determinação das médias mensais e anuais.

O número de focos de calor foi obtido por meio do sistema de detecção do Instituto Nacional de Pesquisas Espaciais/Centro de Previsão de Tempo e Estudos Climáticos (INPE/CPTEC). Os focos de calor são pontos geográficos captados por sensores espaciais na superfície do solo, quando detectado temperatura acima de $47^{\circ} \mathrm{C}$ e área mínima de $900 \mathrm{~m}^{2}$ (Caúla et al., 2015). A detecção de focos de calor ocorreu a partir de uma imagem satélite polar NOAA/AVHRR gerada pelo INPE/CPTEC seguindo três etapas: (i) a leitura primária dos dados brutos recebidos dos satélites, registro, navegação e correção geométrica, corresponde ao pré-processamento; (ii) processamento que compreende a calibração, a detecção de nuvens, o controle de qualidade e a correção atmosférica (Instituto Nacional de Pesquisas Espaciais, 2016). Posteriormente, foi realizado o cálculo dos parâmetros geofísicos (temperatura de brilho, radiância e fator de radiância); (iii)imagens transformadas em parâmetros físicos foram então utilizadas como dados de entrada para a detecção de focos de calor (Deppe et al., 2004). Foi obtido o número de focos de calor diário para o município de Jataí, GO, para os anos de 2007 a 2016, assim como o número de dias em que não foram observados focos de calor. Foi determinado o número total de focos de calor por mês (de janeiro a dezembro dos 10 anos estudados), bem como o número total de focos de calor detectados em cada ano e o número de dias em que foram observados tais focos.

Foram determinados cinco índices de perigo de incêndios florestais: Angstron, Nesterov, Telecyn, Fórmula de Monte Alegre e Fórmula de Monte Alegre Modificada, conforme indicado por Nunes et al. (2006) e Soares (1984).

Os dados (meteorológicos, focos de calor e índices de perigo de incêndios) foram submetidos à análise de variância (ANOVA) e ao teste de Tukey, para separação das médias, a $5 \%$ de significância. Os dados também foram relacionados entre si, por meio da correlação linear de Pearson ( $r$ ) e do coeficiente de determinação para regressão exponencial $\left(R^{2}\right)$, tanto para os dados mensais quanto os anuais.

Para analisar o comportamento de cada índice e definir o de melhor desempenho para o município de Jataí, utilizou-se das seguintes ferramentas estatísticas: o método Skill Score (SS) e a análise da percentagem de sucesso (PS) (Borges et al., 2011; Nunes et al., 2006; Sampaio, 1999). O método SS tem como base o uso de tabelas de contingência, que registram e analisam o padrão de relacionamento entre duas ou mais variáveis e contêm os valores observados e os previstos para um mesmo evento (Torres \& Ribeiro, 2008). Basicamente, este método é a razão da diferença entre os acertos na previsão e o número esperado de acertos e a diferença entre o número de dias observados e o número de dias com previsão de acertos. Considerou-se como não indicativo da probabilidade de ocorrência de incêndios as classes de perigo nulo e pequeno e como indicativos da probabilidade de ocorrência de incêndio as classes de perigo médio, alto e muito alto e perigosíssimo.

\section{RESULTADOS E DISCUSSÃO}

A média anual das variáveis meteorológicas não variou entre os 10 anos analisados, exceto para a velocidade do vento $(p=0,00 ; F=3,25)$. Em 2009, a velocidade média dos ventos foi de $1,9 \mathrm{~m} . \mathrm{s}^{-1}$, enquanto que os demais anos apresentaram valores médios de 2,6 a 3,0 m.s 1. A média para os 10 anos dos valores de temperatura do ar, umidade relativa do ar, temperatura do ponto de orvalho, precipitação e número de dias sem chuva foi de, respectivamente, $28,6^{\circ} \mathrm{C}, 49 \%, 15,4^{\circ} \mathrm{C}, 1629,3 \mathrm{~mm}$.ano-1 e 18,9 dias.mês $\mathrm{s}^{-1}$. A uniformidade das variáveis meteorológicas entre os anos estudados pode auxiliar no refinamento das análises das variações mensais destas variáveis, bem como na eficiência da predição de um índice de perigo de incêndios que seja adequado ao município de Jataí de acordo com as variações meteorológicas mensais.

Para os 10 anos analisados neste estudo, a média dos dados meteorológicos de Jataí estudados variou entre os meses, conforme apresentado na Figura 1. 

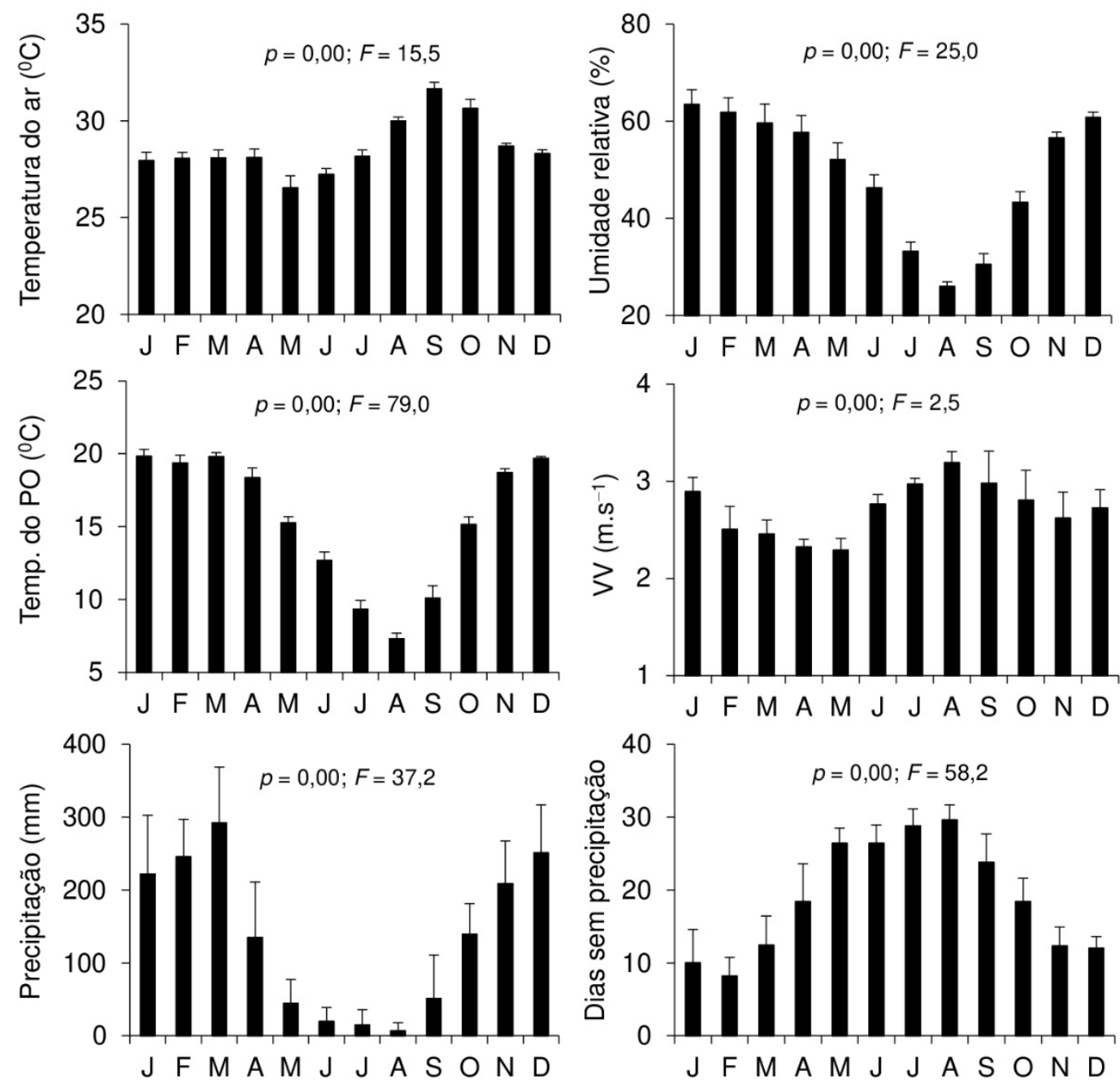

Figura 1. Média mensal da temperatura do $\operatorname{ar}\left({ }^{\circ} \mathrm{C}\right)$, umidade relativa do ar (\%), temperatura do ponto de orvalho $\left(\mathrm{PO},{ }^{\circ} \mathrm{C}\right)$, velocidade do vento $\left(\mathrm{VV}, \mathrm{m} \cdot \mathrm{s}^{-1}\right)$, medidas às $13 \mathrm{~h}$, da precipitação $(\mathrm{mm})$ e número de dias sem chuva do período de 2007 a 2016 para o município de Jataí - GO. Os desvios acima das barras representam o erro padrão da média.

Quanto maior a média mensal temperatura do ar, menores foram os valores de umidade e temperatura do ponto de orvalho. De maio a setembro, da série temporal estudada, observou-se precipitação mensal inferior a $100 \mathrm{~mm}$, o que caracteriza a época seca do município. Neste mesmo período, em mais de 25 dias.mês ${ }^{-1}$ não foram detectados a ocorrência de precipitação. A umidade relativa do ar teve uma média de $49 \%$ durante o período e os meses que apresentaram umidade relativa do ar abaixo da média foram os meses de junho, julho, agosto, setembro e outubro. Os meses que antecedem o período seco do município foram os que apresentaram menores valores de velocidade do vento. As variáveis mensais não diferiram da média histórica destas para o município de Jataí (Instituto Nacional de Meteorologia, 2017). O estudo das variáveis meteorológicas é importante para determinar o perigo de ocorrência de incêndios, pois é possível identificar os dias e épocas de maior probabilidade de ocorrência de incêndios, possibilitando assim tomar medidas para reduzir o potencial de danos do fogo (Soares \& Batista, 2007).

O número total de focos de calor detectados por ano não variou significativamente de 2007 a 2016, com $p=0,13 ; F=1,59$ (Figura 2). Isto pode ter ocorrido provavelmente devido à variabilidade mensal do número de focos de calor observado em cada ano, 
assim como às características meteorológicas regulares durante os 10 anos utilizados neste estudo.
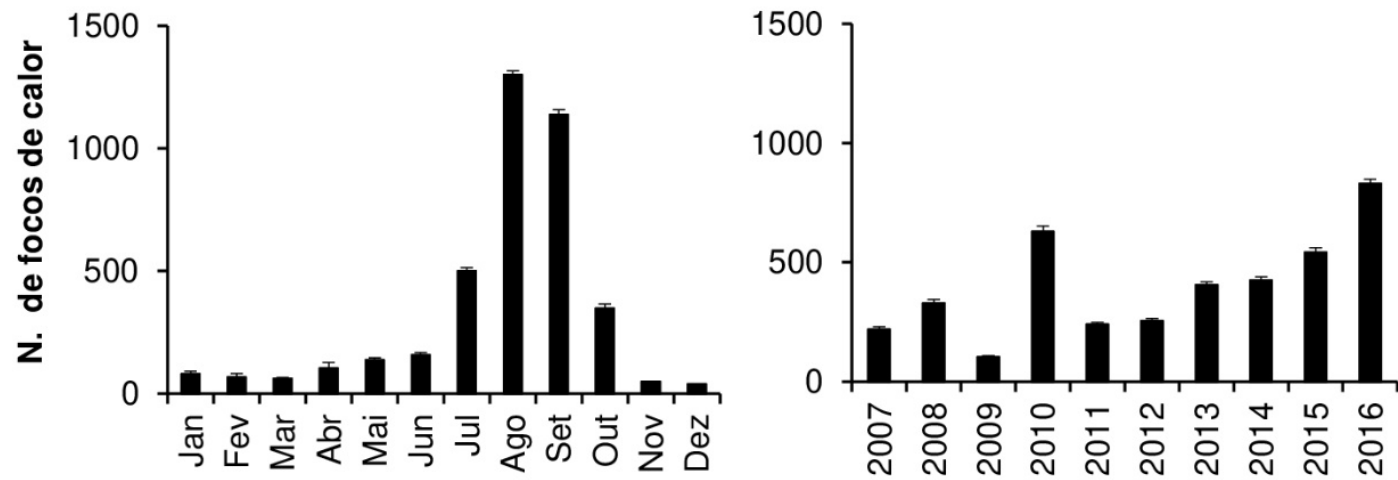

Figura 2. Focos de calor detectados por mês e por ano no município de Jataí - GO no período de 2007 a 2016. Os desvios acima das barras representam o erro padrão da média.

No período de 2007 a 2016, foram detectados 3.984 focos de calor no município de Jataí, dos quais aproximadamente $80 \%$ deles ocorreram nos meses de julho, agosto, setembro e outubro (Figura 2).

Houve diferença estatística significativa entre os valores mensais do número de focos de calor $(p=0,00 ; F=20,50)$. Os meses de agosto e setembro foram os que apresentaram o maior número de focos, enquanto os meses de novembro a junho foram aqueles em que foram detectadas quantidades inferiores de focos de calor. Isto era esperado porque os meses caracterizados com secos foram aqueles em que houve maior número de focos de calor, devido à baixa umidade do ar, ao maior número de dias sem chuva, associados à baixa umidade do material combustível e elevada temperatura do ar, entre outras variáveis. Apesar do número de focos de calor detectados nem sempre associarem-se com a ocorrência de incêndios, a possibilidade de ocorrência de incêndios pode ser elevada quando são registrados muitos focos de calor em uma mesma localidade (Tomzhinski et al., 2011).

O número de dias por mês em que foi observado perigo de incêndios variou entre os diferentes índices e entre os meses dos anos entre 2007 e 2016 (Figura 3).

De maneira geral, para todos os índices, de maio a setembro foram observados os maiores graus de perigo de incêndios. Por outro lado, o grau de perigo de incêndios foi reduzido nos meses de novembro a abril. Geralmente, nos meses em que há maior precipitação ocorre menor possibilidade de ocorrer incêndios, como observado por White \& White (2016).

O número de dias por ano com diferentes graus de perigo de incêndios não variou significativamente entre os anos estudados (Figura 4).

O índice de Angstron foi o que apresentou maior número de dias por ano com perigo de incêndio de 2007 a 2016, com valores superiores a 200 dias.ano $^{-1}$. Os outros

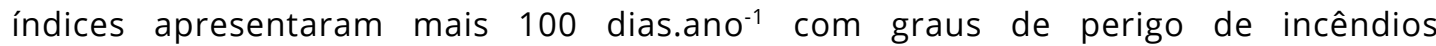
classificados elevados. Porém, se considerarmos as diferentes classes dos índices de Telecyn, Nesterov, FMA e FMA+, haveria a probabilidade de ocorrência de incêndio em mais de 200 dias.ano-1 $^{-1}$. De maneira geral, não houve variação das diferentes classes de perigo de incêndios entre os anos (Figura 4), diferente dos resultados mostrados por Casavecchia et al. (2019).

Observou-se que as médias mensais de todas variáveis meteorológicas estudadas correlacionaram-se linear e exponencialmente com a média do número de focos de calor, exceto para o número de dias sem chuva (Tabela 1). O mesmo não ocorreu para as médias anuais das variáveis meteorológicas (Tabela 1). 

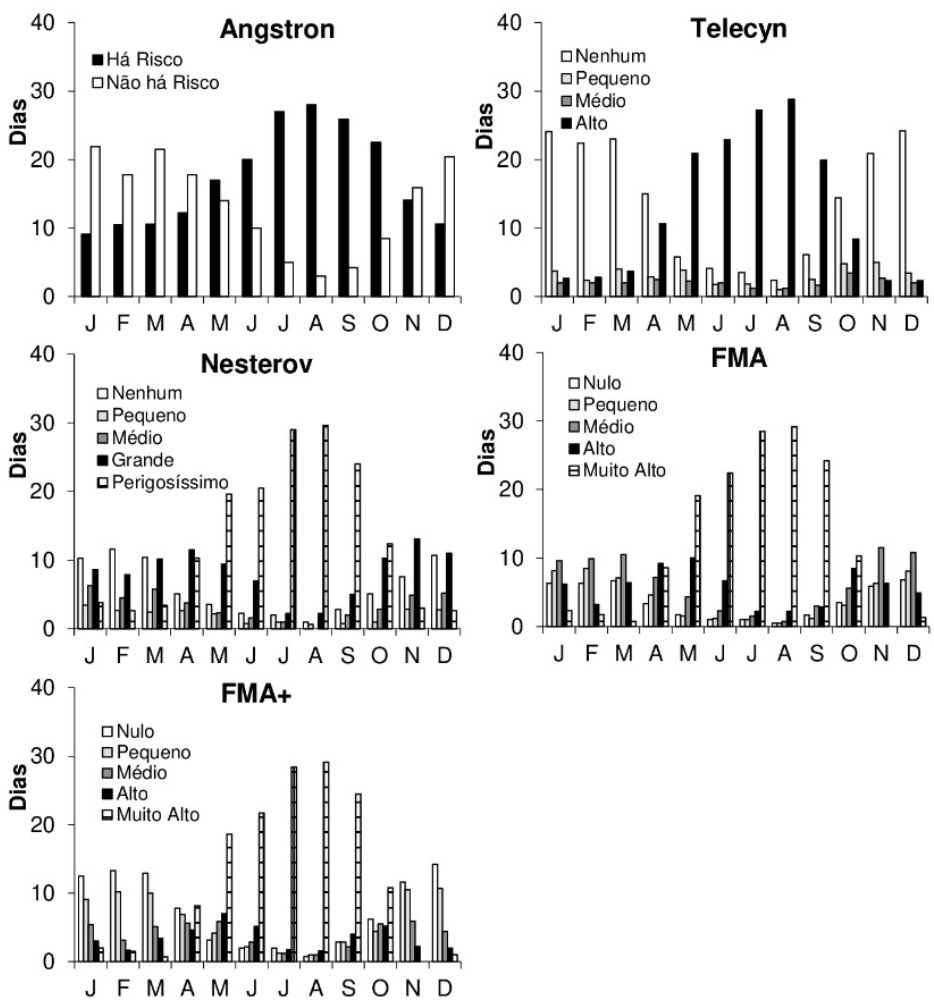

Figura 3. Dias por mês em que foram observados perigo de incêndios a partir dos índices de Angstron; Telecyn; Nesterov; Fórmula de Monte Alegre (FMA) e Fórmula de Monte Alegre Modificada (FMA+), para o município de Jataí-GO no período de 2007 a 2016.

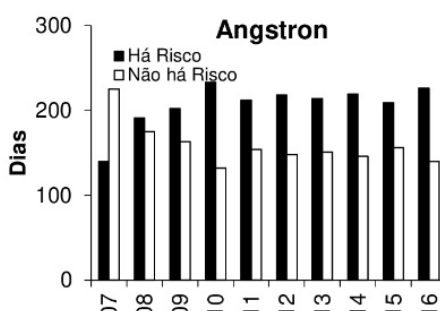

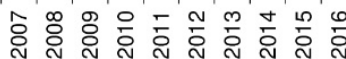
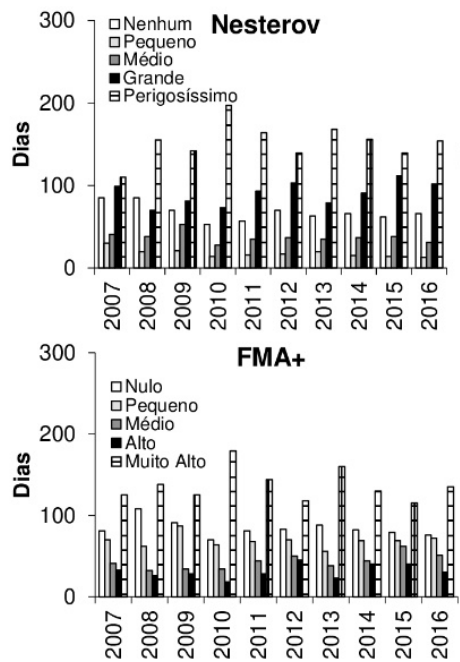

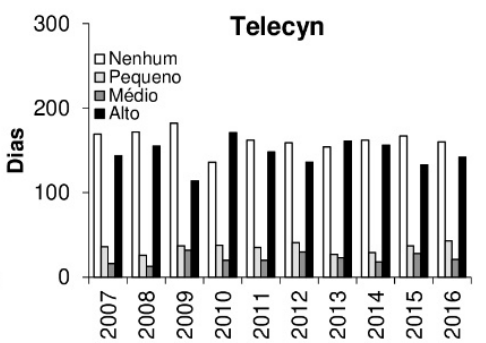

300

口Nulo

ádio

- Alto
Mlto

200 - Muito Alto

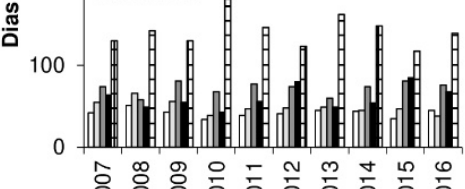

Figura 4. Número de dias por ano em que foram observados perigo de incêndios a partir do cálculo dos índices de perigo de incêndios (Angstron; Telecyn; Nesterov; Fórmula de Monte Alegre (FMA) e Fórmula de Monte Alegre Modificada (FMA+)) para o município de Jataí-GO no período de 2007 a 2016. 
Tabela 1. Correlação linear de Pearson ( $r$ e coeficiente de determinação para regressão exponencial $\left(R^{2}\right)$ entre o número de focos de calor (mensal e anual) e as variáveis meteorológicas e os índices de perigo de incêndios (Angstron, Telecyn, Nesterov, Fórmula de Monte Alegre - FMA e Fórmula de Monte Alegre Modificada - FMA+) para Jataí-GO no período de 2007 a 2016.

\begin{tabular}{ccccc}
\hline & \multicolumn{2}{c}{ Focos mensais } & \multicolumn{2}{c}{ Focos anuais } \\
\hline Variáveis meteorológicas & $\mathbf{r}$ & $\mathbf{R}^{\mathbf{2}}$ & $\mathbf{r}$ & $\mathbf{R}^{\mathbf{2}}$ \\
Temperatura do $\operatorname{ar}\left({ }^{\circ} \mathrm{C}\right)$ & $0,70^{*}$ & 0,41 & $0,52^{\text {ns }}$ & 0,31 \\
Umidade relativa do $\operatorname{ar}(\%)$ & $-0,89^{* *}$ & 0,92 & $-0,48^{n s}$ & 0,25 \\
Temperatura do ponto de orvalho $\left({ }^{\circ} \mathrm{C}\right)$ & $-0,85^{* *}$ & 0,87 & $-0,41^{n s}$ & 0,31 \\
Velocidade do vento $\left(\mathrm{m} \cdot \mathrm{s}^{-1}\right)$ & $0,73^{*}$ & 0,47 & $0,36^{n s}$ & 0,34 \\
Precipitação pluviométrica $(\mathrm{mm})$ & $-0,63^{* *}$ & 0,63 & $-0,29^{n s}$ & 0,09 \\
Número de dias sem chuva & $0,65^{n s}$ & 0,61 & $0,52^{\text {ns }}$ & 0,26 \\
Índices de perigo de incêndios & & & & \\
Angstron & $0,82^{* *}$ & 0,87 & $0,51^{n s}$ & 0,21 \\
Telecyn & $0,67 *$ & 0,66 & 0,50 ns & 0,40 \\
Nesterov & $0,67^{* *}$ & 0,69 & $0,300^{n s}$ & 0,15 \\
FMA & $0,66^{* *}$ & 0,67 & $0,25^{n s}$ & 0,13 \\
FMA+ & $0,67^{* *}$ & 0,71 & $0,66^{n s}$ & 0,44
\end{tabular}

*,** Significant at the $5 \%$ and $1 \%$ probability levels respectively; ns, not significantly different.

A umidade relativa do ar, a temperatura do ponto de orvalho e a precipitação correlacionaram-se negativamente com o número de focos mensais e anuais, diferentemente das outras variáveis. O coeficiente de determinação para a regressão exponencial $\left(R^{2}\right)$ das variáveis meteorológicas e a média mensal e anual do número de focos foram inferiores aos valores de correlação ( $r$ ). A média mensal da umidade relativa do ar e da temperatura do ponto de orvalho foram as variáveis que mais se correlacionaram com o número de focos de calor. Em estudo realizado por Soriano et al. (2015), para sub-região de Nhecolândia - MS, as variáveis que melhor se correlacionaram com o número de ocorrências de focos de calor foram a velocidade do vento e a umidade relativa do ar, apresentando, respectivamente, valores de $r=0,79$ e -0,69. Para o coeficiente de determinação da regressão exponencial, os autores encontraram que as variáreis que melhor se ajustaram foram velocidade do vento $\left(R^{2}\right.$ $=0,84)$ e umidade relativa do $\operatorname{ar}\left(R^{2}=0,61\right)$.

Os resultados obtidos na correlação entre os focos de calor e as variáveis meteorológicas eram esperados, já que os meses com maiores números de focos de calor são os que apresentam baixa precipitação pluviométrica, baixa umidade relativa do ar e baixa temperatura de ponto de orvalho, possibilitando assim que o material combustível fique mais suscetível ao fogo. Os resultados do coeficiente de determinação apresentaram ajuste de moderado a muito forte $(0,41$ - 0,92) com todas as médias mensais das variáveis meteorológicas. Por outro lado, os coeficientes de determinação das médias anuais das variáveis meteorológicas foram inferiores a 0,35.

Todos os índices estudados correlacionaram-se com o número de dias em que foram registrados focos de calor (Tabela 1), sendo o índice de Angstron o que apresentou o maior coeficiente de correlação. As médias mensais das variáveis meteorológicas obtiveram um bom ajustamento com os focos mensais, assim como os índices, considerando que valores de $r$ acima de 0,6 mostram que as variáveis possuem forte relação. A baixa relação entre 0 número de dias por ano com focos de calor registrados e os índices pode ser explicada pela variação entre os meses de cada ano.

A correlação das médias mensais e anuais das variáveis meteorológicas com os valores dos índices de perigo de incêndios pode ser observada na Tabela 2 . Apenas as médias mensais da temperatura do ar e velocidade do vento e o número de dias sem chuva por ano não apresentaram correlações significativas com os valores dos índices de perigo de incêndios estudados. 
Tabela 2. Correlação de Pearson ( $r$ ) entre as variáveis meteorológicas (médias mensais e anuais) e o número de dias com probabilidade de ocorrência de incêndios calculados por meio de índices de perigo de incêndios (Angstron (B), Telecyn (I), Nesterov (G), Fórmula de Monte Alegre (FMA) e Fórmula de Monte Alegre Modificada (FMA+)) para Jataí-GO de 2007 a 2016.

\begin{tabular}{|c|c|c|c|c|c|}
\hline Médias mensais & B & $\mathbf{I}$ & G & FMA & FMA+ \\
\hline Temperatura do $\operatorname{ar}\left({ }^{\circ} \mathrm{C}\right)$ & $0,54^{n s}$ & $0,14^{\text {ns }}$ & $0,28^{n s}$ & $0,23^{\text {ns }}$ & $0,23^{n s}$ \\
\hline Umidade relativa do ar (\%) & $-0,96 * *$ & $-0,57 * \star$ & $-0,84 * *$ & $-0,42 * *$ & $-0,64 * *$ \\
\hline Temperatura do ponto de orvalho $\left({ }^{\circ} \mathrm{C}\right)$ & $-0,97 * *$ & $-0,94 * *$ & $-0,91 * *$ & $-0,91 * *$ & $-0,92 * *$ \\
\hline Velocidade do vento $\left(\mathrm{m} . \mathrm{s}^{-1}\right)$ & $0,68^{*}$ & $0,46^{n s}$ & $0,47^{n s}$ & $0,43^{\text {ns }}$ & $0,46^{n s}$ \\
\hline Precipitação pluviométrica (mm) & $-0,86 * *$ & $-0,97 * *$ & $-0,95 * *$ & $-0,97 * *$ & $-0,97 * *$ \\
\hline Número de dias sem chuva & $0,87^{*}$ & $0,99 * *$ & $0,98 * *$ & $0,99 * *$ & $0,98 * *$ \\
\hline \multicolumn{6}{|l|}{ Médias anuais } \\
\hline Temperatura do $\operatorname{ar}\left({ }^{\circ} \mathrm{C}\right)$ & $0,93 * *$ & $0,48^{n s}$ & $0,90 *$ & $0,63^{n s}$ & $0,76^{n s}$ \\
\hline Umidade relativa do ar (\%) & $-0,96 * *$ & $-0,57 * *$ & $-0,84 * *$ & $-0,42 * *$ & $-0,64 * *$ \\
\hline Temperatura do ponto de orvalho $\left({ }^{\circ} \mathrm{C}\right)$ & $-0,55^{\star}$ & $-0,58 * *$ & $-0,47 * *$ & $-0,38 * *$ & $-0,50 * *$ \\
\hline Velocidade do vento $\left(\mathrm{m} . \mathrm{s}^{-1}\right)$ & $0,21^{n s}$ & $0,54^{*}$ & $0,23 * *$ & $0,18 * *$ & $0,61 * *$ \\
\hline Precipitação pluviométrica (mm) & $0,07^{\text {ns }}$ & $-0,17^{*}$ & $-0,31 * *$ & $-0,60 * *$ & $-0,50 * *$ \\
\hline Número de dias sem chuva & $0,23^{\text {ns }}$ & $0,50^{n s}$ & $0,51^{\text {ns }}$ & $0,84^{\text {ns }}$ & $0,74^{n s}$ \\
\hline
\end{tabular}

*,** Significant at the $5 \%$ and $1 \%$ probability levels respectively; ns, not significantly different.

A umidade relativa do ar, a temperatura do ponto de orvalho e a precipitação pluviométrica mensal foram inversamente proporcionais aos índices de perigo de incêndio. $\mathrm{O}$ número de dias sem chuvas (valor mensal) teve forte correlação (acima de 0,87) com todos os índices. A velocidade do vento apresentou correlação significativa apenas com o índice de Angstron, enquanto que a relação entre a média mensal da temperatura do ar não foi significativa com nenhum índice estudado. Todas as variáveis estudadas, direta ou indiretamente, influenciam a possibilidade de ocorrência de incêndios, seja por participarem dos cálculos dos índices ou por terem efeito sobre os componentes que dão origem aos incêndios.

O número de dias em que foram observados focos de calor e que foi verificado algum grau de perigo de incêndio variou entre as classes dos índices de perigo de incêndios estudados (Tabela 3).

Tabela 3. Dias com focos de calor classificados de acordo com as classes de perigo de incêndios dos índices de Angstron (B), Telecyn (I), Nesterov (G), Fórmula Monte Alegre (FMA) e Fórmula Monte Alegre Modificada (FMA+) e probabilidade de ocorrência de perigo de incêndios para Jataí-GO de 2007 a 2016.

\begin{tabular}{ccccccccccc}
\hline & \multicolumn{4}{c}{ Dias com focos de calor } & \multicolumn{7}{c}{ Probabilidade } \\
\cline { 2 - 11 } Classes de perigo & B & I & G & FMA & FMA+ & B & I & G & FMA & FMA+ \\
\hline I II & 121 & 133 & 34 & 20 & 50 & - & - & - & - & - \\
III & 667 & - & - & - & - & 0,85 & - & - & - & - \\
IV & - & 80 & 8 & 33 & 73 & - & 0,10 & 0,01 & 0,04 & 0,09 \\
V & - & 53 & 40 & 82 & 78 & - & 0,07 & 0,05 & 0,10 & 0,10 \\
VI & - & 522 & 149 & 129 & 69 & - & 0,66 & 0,19 & 0,16 & 0,09 \\
Total & - & - & 557 & 524 & 518 & - & - & 0,71 & 0,67 & 0,66 \\
& 788 & 788 & 788 & 788 & 788 & 0,85 & 0,83 & 0,96 & 0,97 & 0,94 \\
\hline
\end{tabular}

Classes de perigo de incêndios: I - nenhum ou nulo, II - há perigo, III - Pequeno, IV - Médio, V - Alto ou grande, VI muito alto ou perigosíssimo. 
Foram registrados 788 dias com focos de calor durante o período estudado, enquanto que cada um dos diferentes índices previu números distintos de dias com perigo de incêndios (Tabela 3), como, por exemplo, a FMA que apresentou a previsão de 768 dias com perigo de incêndios. Considerando os 788 dias com focos registrados e os 768 dias com perigo de incêndios previstos, a probabilidade de acerto da FMA foi de 97\%. Dessa forma, todos os índices apresentaram probabilidade de acerto, sobressaindo-se a FMA, G e FMA+.

Além disso, observou-se que todos os índices apresentaram probabilidade de detectar os focos de calor nos graus de perigo de incêndios classificados como alto, grande, muito alto ou perigosíssimo (Tabela 3). Assim, como o grau de perigo pequeno de incêndios obteve baixa probabilidade quando associados aos dias com focos de calor (valores menores que 10\%), considerou-se como não indicativo da probabilidade de ocorrência de incêndios as classes de perigo nulo e pequeno, e como indicativos da probabilidade de ocorrência de incêndio as classes de perigo médio, alto ou grande e muito alto e perigosíssimo, para a análise dos dados de porcentagem de sucesso e Skill Score da Tabela 4.

O índice de Telecyn, seguido dos de Angstron e FMA+, foram os que apresentaram as maiores probabilidades de acerto dos dias em que foram e não foram encontrados focos de incêndios. Consequentemente, estes índices apresentaram melhores resultados de Skill Score e porcentagem de sucesso (Tabela 4). Para o índice de Telecyn, dos 3653 dias, 1681 dias apresentaram previsão de ocorrência de incêndios, sendo que 575 foram dias em que foram observados focos de calor e 213 dias em que também foram observados focos de calor, o índice não havia previsto. Para o índice de Angstron foram registrados 2064 dias em que estava previsto a ocorrência de incêndios, sendo que em 667 dias foram observados focos de calor, enquanto que 121 dias apesar do índice não ter previsto, também ocorreram os focos de calor. A FMA+indicou 2110 dias com previsão de ocorrência de incêndios, onde em 665 dias foram observados os focos de calor, e 123 dias em que não estava previsto a ocorrência de incêndios e ocorreram os focos de calor.

Tabela 4. Porcentagem de sucesso (\%) e valores de skill score (SS) dos índices de previsão de ocorrência de incêndios (Angstron, Telecyn, Nesterov, Fórmula de Monte Alegre - FMA e Fórmula de Monte Alegre Modificada - FMA+) relacionados ao número de focos de calor observados em Jataí-GO de 2007 a 2016.

\begin{tabular}{|c|c|c|c|c|c|}
\hline \multirow{2}{*}{\multicolumn{2}{|c|}{ Índice de perigo }} & \multicolumn{2}{|c|}{ Focos de calor } & \multirow{3}{*}{$\begin{array}{c}\text { Skill Score } \\
0,2261\end{array}$} & \multirow{3}{*}{$\begin{array}{c}\text { Porcentagem } \\
\text { de sucesso }\end{array}$} \\
\hline & & \multirow{2}{*}{$\begin{array}{c}\text { Observado } \\
667\end{array}$} & \multirow{2}{*}{$\begin{array}{c}\text { Não observado } \\
1397\end{array}$} & & \\
\hline Angstron & Previsto & & & & \\
\hline & Não previsto & 121 & 1468 & & \\
\hline \multirow[t]{2}{*}{ Telecyn } & Previsto & 575 & 1106 & 0,2436 & 63,89 \\
\hline & Não previsto & 213 & 1759 & & \\
\hline \multirow[t]{2}{*}{ Nesterov } & Previsto & 746 & 2054 & 0,1193 & 42,62 \\
\hline & Não previsto & 42 & 811 & & \\
\hline \multirow[t]{2}{*}{ FMA } & Previsto & 735 & 2009 & 0,1219 & 43,55 \\
\hline & Não previsto & 53 & 856 & & \\
\hline \multirow[t]{2}{*}{ FMA+ } & Previsto & 665 & 1445 & 0,2111 & 57,08 \\
\hline & Não previsto & 123 & 1420 & & \\
\hline
\end{tabular}

Soriano et al. (2015), em estudo realizado na sub-região da Nhecolândia, pantanal sul mato-grossense, observaram 697 dias em que foram registrados focos de calor. Neste caso, a FMA registrou ocorrência de 691 dias, gerando uma porcentagem de 99\% de acerto dos focos de calor; seguido do índice de Nesterov e de Angstron, que tiveram 98 e $84 \%$ de acertos dos focos de calor. Em trabalho realizado por Sampaio (1999), para a região de Agudos - SP, o valor de Skill Score encontrado para os índices de Nesterov, Telecyn, FMA e FWI (índice do Canadá) foram respectivamente 0,1024; 0,1369; 0,0607 e 0,1838. Borges et al. (2011), em um plantio de eucalipto no norte do Espírito Santo- ES, apresentaram Skill Score para a FMA+ 
variando de 0,1626 a 0,2055, enquanto para os outros índices o maior valor alcançado foi de 0,1503, obtido pela equação de Nesterov. A FMA+ apresentou valores de PS variando de 51,54 a 56,47\%, enquanto para os outros índices o valor máximo obtido foi de $46,75 \%$, para o índice de Nesterov. Em um estudo realizado na área urbana de Juiz de Fora - MG, por Torres et al. (2009), o índice que apresentou maior porcentagem de sucesso foi o P-EVAP (referente à variável calculada a partir da precipitação e evaporação), com $56 \%$ de acertos, seguido do EVAP/P (54,2\%), Telecyn (43,9\%), FMA (35,3\%) e Nesterov (34,5\%). Apesar de serem regiões distintas, com diferentes características climáticas, alguns valores de porcentagem de sucesso e Skill Score encontrados neste estudo foram similares aos citados.

\section{CONCLUSÃO}

Os índices de Telecyn, Angstron e FMA+ foram os mais eficientes para o município de Jataí, por meio da análise Skill Score e porcentagem de sucesso.

\section{REFERÊNCIAS}

Borges, T. S., Fieldles, N. C., Santos, A. R., Loureiro, E. B., \& Mafia, R. G. (2011). Desempenho de alguns índices de risco de incêndios em plantios de eucalipto no norte do Espírito Santo. Floresta e Ambiente, 18(2), 153-159.

Casavecchia, B. H., Souza, A. P., Stangerlin, D. M., Uliana, E. M., \& Melo, R. R. (2019). Índices de perigo de incêndios em uma área de transição Cerrado-Amazônia. Revista de Ciências Agrárias, 42(3), 842-854.

Caúla, R. H., Oliveira-Júnior, J. F., Lyra, G. B., Delgado, R. C., \& Heilbron Filho, P. F. L. (2015). Overview off fire foci causes and locations in Brazil based on meteorological satellite data from 1998 to 2011. Environmental Earth Sciences, 74(2), 1497-1508.

Deppe, F., Paula, E. V., Meneghette, C. R., \& Voserau, J. (2004). Comparação de índice de risco de incêndio florestal com focos de calor no estado do Paraná. Floresta, 34(2), 119-126.

Durigan, G., \& Ratter, J. A. (2016). The need for a consistent fire policy for Cerrado conservation. Journal of Applied Ecology, 53(1), 11-15. http://dx.doi.org/10.1111/1365-2664.12559.

Frizzo, T. L. M., Bonizário, C., Borges, M. P., \& Vasconcelos, H. L. (2011). Revisão dos efeitos do fogo sobre a fauna de formações savânicas do Brasil. Oecologia Australis, 15(2), 365-379.

Instituto Brasileiro de Geografia e Estatística - IBGE. (2017). Produção agrícola - Lavoura Temporária 2017. Recuperado em 3 de setembro de 2019, de https://cidades.ibge.gov.br/brasil/go/jatai/pesquisa/14/0?tipo=ranking\&indicador=10368

Instituto Nacional de Meteorologia - INMET. (2017). Dados meteorológicos de estações automáticas de 2007 a 2016. Recuperado em 3 de janeiro de 2017, de http://www.inmet.gov.br/portal/index.php?r=home/page\&page=rede_estacoes_auto_graf

Instituto Nacional de Pesquisas Espaciais - INPE Centro de Previsão de Tempo e Estudos Climáticos CPTEC. (2016). Portal do Monitoramento de Queimadas e Incêndios. Recuperado em 2 de agosto de 2017, de http://www.inpe.br/queimadas

Medeiros, M. B., \& Miranda, H. S. (2005). Mortalidade pós-fogo em espécies lenhosas de campo sujo submetido a três queimadas prescritas anuais. Acta Botanica Brasílica, 19(3), 493-500.

Nunes, J. R. S., Soares, R. V., \& Batista, A. C. (2006). FMA+ - um novo índice de perigo de incêndios florestais para o estado do Paraná, Brasil. Floresta, 36(1), 75-91.

Sampaio, O. B. (1999). Análise da eficiência de quatro índices na previsão de incêndios florestais para a região de Agudos - SP (Tese de doutorado). Universidade Federal do Paraná, Curitiba.

Schmidt, I. B., Fonseca, C. B., Ferreira, M. C., \& Sato, M. N. (2016). Implementação do programa piloto de manejo integrado do fogo em três unidades de conservação do Cerrado. Biodiversidade Brasileira, $6(2), 55-70$.

Soares, R. V. (1984). Perfil dos incêndios florestais no Brasil em 1983. Brasil Florestal, 14(58), 31-42.

Soares, R. V., \& Batista, A. C. (2007). Incêndios florestais: controle, efeitos e uso do fogo (264 p.). Curitiba.

Soriano, B. M. A., Daniel, O., \& Santos, S. A. (2015). Eficiência de índices de risco de incêndios para o pantanal sul-mato-grossense. Ciência Florestal, 25(4), 809-816. 
Tomzhinski, G. W., Coura, P. H. F., \& Fernandes, M. C. (2011). Avaliação da detecção de focos de calor por sensoriamento remoto para o Parque Nacional do Itatiaia. Biodiversidade Brasileira, 1(2), 201 . 211.

Torres, F. P. T., Lima, G. S., Martins, S. V., \& Valverde, S. R. (2017). Analysis of efficiency of fire danger index in forest fire prediction. Revista Árvore, 15(2), 24-34.

Torres, F. T. P., \& Ribeiro, G. A. (2008). Índices de risco de incêndios florestais em Juiz de Fora/MG. Floresta e Ambiente, 15(2), 30-39.

Torres, F. T. P., Ribeiro, G. A., Martins, S. M., \& Lima, G. S. (2009). Relações entre incêndios em vegetação e elementos meteorológicos na cidade de Juiz de Fora, MG. Revista Brasileira de Meteorologia, 24, 379-389.

Torres, F. T. P., Ribeiro, G. A., Martins, S. V., \& Lima, G. S. (2011). Correlações entre os elementos meteorológicos e as ocorrências de incêndios florestais na área urbana de Juiz de Fora, MG. Revista Árvore, 35, 143-150.

White, B. L. A., \& White, L. A. S. (2016). Queimadas controladas e incêndios florestais no estado de Sergipe, Brasil, entre 1999 e 2015. Floresta, 46(4), 561-570.

Contribuição dos autores: DMG: conceituação, curadoria de dados, análise formal, investigação, escrita primeira redação; DPD: conceituação, curadoria de dados, análise formal, investigação, metodologia, supervisão, escrita - revisão e edição. 